ORIGINAL ARTICLE

\title{
Oral shedding of herpes simplex virus type 2
}

\author{
A Wald, M Ericsson, E Krantz, S Selke, L Corey
}

Sex Transm Infect 2004;80:272-276. doi: 10.1136/sti.2003.007823

See end of article for authors' affiliations

......................

Correspondence to: Anna Wald, MD, MPH, University of Washington Virology Research Clinic, 600 Broadway, Suite 400, Seattle, WA 98122, USA; annawald@u.washington. edu

Accepted for publication 9 January 2004

\begin{abstract}
Objectives: Herpes simplex virus (HSV) 1 and HSV-2 reactivate preferentially in the oral and genital area, respectively. We aimed to define frequency and characteristics associated with oral shedding of HSV-2. Methods: Demographic, clinical and laboratory data of patients with documented HSV-2 infection and at least one oral viral culture obtained were selected from the University of Washington Virology Research Clinic database.

Results: Of 1388 people meeting the entry criteria, $44(3.2 \%)$ had HSV-2 isolated at least once from their mouths. In comparison with the 1344 people who did not have HSV-2 isolated from their mouth, participants with oral HSV-2 were more likely to be male (OR=1.9, 95\% $\mathrm{Cl} 1.0$ to 3.7), HIV positive $(\mathrm{OR}=2.9,95 \% \mathrm{Cl} 1.4$ to 6.0 ), and homosexual $(\mathrm{OR}=2.2,95 \% \mathrm{Cl} 1.1$ to 4.2$)$, and to have collected a larger number of oral specimens (median $32 \vee 4, \mathrm{p}<0.001$ ). Of the 58 days with oral HSV-2 isolation, 15 $(25 \%)$ occurred during newly acquired HSV-2 infection, $12(21 \%)$ during a recurrence with genital lesions, three $(5 \%)$ during a recurrence with oral lesions, and three $(5 \%)$ during a recurrence with oral and genital lesions; 25 (43\%) occurred during asymptomatic shedding. Oral HSV-2 was found less frequently than oral HSV-1 $(0.06 \% \vee 1 \%, \mathrm{p}<0.001)$ in people with HSV-1 and HSV-2 antibody, and less frequently than genital HSV-2 $(0.09 \% \vee 7 \%, p<0.001)$.

Conclusions: Oral reactivation of HSV-2 as defined by viral isolation is uncommon and usually occurs in the setting of first episode of genital HSV-2 or during genital recurrence of HSV-2.
\end{abstract}

\section{Participants, setting, and sample collection}

The study design is a case series from observational cohort studies of participants seen from 1974 to 2002 at the University of Washington Virology Research Clinic. For this analysis we selected patients with HSV-2 infection documented by serology or viral isolation (with or without HSV-1 infection) who had at least one viral culture obtained from the mouth. All patients seen in the clinic had standardised demographic and clinical information obtained. At each clinic visit, a genital examination was done and samples for viral cultures were collected using Dacron swabs from the genital and oral area. The presence of genital lesions was noted by clinician during the visits, or noted in the patient diary in between visits. Patients were requested to return to the clinic at 3-12 month intervals depending on the protocol in which they were enrolled. A subset of patients participated in home culture protocols, in which the subjects obtained daily swabs for oral as well as genital secretions. The techniques for these studies have been described previously..$^{4-9}$ The patients enrolled in daily home culture after resolution of first episode infection. The oral and genital samples obtained in the clinic, as well as those obtained during home sampling, were obtained without regard to the presence or absence of lesions. Charts of patients with oral symptomatic shedding caused by HSV-2 were reviewed to confirm the presence or absence of lesions in the genital or oral area.

\section{Laboratory methods}

Specimens for viral culture were delivered to the laboratory twice daily from the clinic and three times weekly from participants in daily home cultures. The samples were inoculated onto tissue culture and all isolates were defined with monoclonal antibodies as described previously. ${ }^{10} \mathrm{HSV}$ western blot was used to define antibodies to HSV-1 and HSV-2. ${ }^{11}$

\section{Definitions and statistical methods}

Viral shedding was defined as isolation of HSV from mucosal sites. The viral shedding was categorised as either symptomatic (with lesions), or subclinical (asymptomatic). HSV infection was categorised using clinical and laboratory findings. Patients were defined as having first episodes of genital herpes if they had newly acquired HSV infection with a compatible clinical syndrome and viral isolation but no antibodies to that HSV type. Recurrent infection was defined as reactivation of previously acquired HSV infection.

For two group comparisons, person level continuous variables were compared using the Mann-Whitney two sample test, and person level categorical variables were compared with odds ratios (OR), with confidence intervals, and $p$ values. Logistic regression was used for multivariate analyses comparing those who shed HSV-2 orally with those who did not. Shedding rates were calculated as the ratio of number of positive days to the number of days with culture results at a particular site. Comparisons between oral HSV-2 shedding and genital HSV-2 shedding used paired testing; number of people were compared using McNemar's test, and rates of shedding were compared by testing per person proportion of positive days using the Wilcoxon signed rank test. Oral HSV-2 shedding and oral HSV-1 shedding were compared in the same way. 


\begin{tabular}{|c|c|c|c|c|}
\hline & \multicolumn{4}{|c|}{ All HSV-2 seropositive $(n=1388)$} \\
\hline & \multicolumn{4}{|c|}{ Oral HSV-2 isolated } \\
\hline & Yes $(n=44)$ & No $(n=1344)$ & Total & p Value \\
\hline Age, median (range) & $33(18-55)$ & $32(15-76)$ & $32(15-76)$ & 0.48 \\
\hline \multicolumn{5}{|l|}{ Sex } \\
\hline $\begin{array}{l}\text { Male } \\
\text { Female }\end{array}$ & $\begin{array}{l}27(61 \%) \\
17(39 \%)\end{array}$ & $\begin{array}{l}606(45 \%) \\
738(55 \%)\end{array}$ & $\begin{array}{l}633(46 \%) \\
755(54 \%)\end{array}$ & 0.03 \\
\hline \multicolumn{5}{|l|}{ Race } \\
\hline White & $40(91 \%)$ & $1126(84 \%)$ & $1166(84 \%)$ & 0.2 \\
\hline Other & $4(9 \%)$ & $218(16 \%)$ & $222(16 \%)$ & \\
\hline \multicolumn{5}{|l|}{ Sexual orientation* } \\
\hline Heterosexual & $27(61 \%)$ & 971 (77\%) & 998 (77\%) & 0.01 \\
\hline Homosexual & $17(39 \%) \dagger$ & $285(23 \%)$ & $302(23 \%) \ddagger$ & \\
\hline No of lifetime sex partners, median (range) & $15(2-300)$ & $15(1-998)$ & $15(1-998)$ & 0.58 \\
\hline Age at sexual debut, median (range) & $17(12-23)$ & $17(4-33)$ & $17(4-33)$ & 0.92 \\
\hline \multicolumn{5}{|l|}{ HIV status } \\
\hline Positive & $12(27 \%)$ & $155(12 \%)$ & $167(12 \%)$ & 0.002 \\
\hline Negative & $32(73 \%)$ & $1189(88 \%)$ & $1221(88 \%)$ & \\
\hline \multicolumn{5}{|l|}{ Serology } \\
\hline HSV-2 & $25(57 \%)$ & $778(58 \%)$ & $803(58 \%)$ & 0.9 \\
\hline HSV-1 HSV-2 & $19(43 \%)$ & $566(42 \%)$ & $585(42 \%)$ & \\
\hline No of oral cultures per person, median (range) & $32(1-520)$ & $4(1-665)$ & $4(1-665)$ & 0.001 \\
\hline
\end{tabular}

\section{RESULTS}

\section{Subjects and days with HSV-2 reactivation in the mouth}

Of the 3832 patients with HSV-2 infection seen in the clinic between June 1974 and April 2002, 1388 (35\%) had at least one oral culture obtained; the demographic and clinical characteristics of the cohort are summarised in table 1. The median age was 32 (15-76); women comprised 54\% of the participants. Most participants were white. Men who have sex with men (MSM; $\mathrm{n}=246)$ and woman who have sex with women $(n=56)$ accounted for $23 \%$ of the subjects and $12 \%$ had known HIV infection. The median number of oral cultures obtained from individual patients was four (range 1-665). Overall, 39264 days of oral samples obtained for viral culture were included in the analysis.

Of 1388 participants, 44 (3.2\%) had HSV-2 isolated from the mouth on at least one occasion. In comparison with people who never had HSV-2 isolated from the mouth, subjects with oral HSV-2 were more likely male, OR $=1.9$ (95\% CI 1.0 to $3.7 ; \mathrm{p}=0.03)$, HIV positive, OR $=2.9(95 \% \mathrm{CI}$ 1.4 to $6.0 ; \mathrm{p}=0.002$ ) and homosexual $v$ heterosexual,

Table 2 Days with oral HSV-2 shedding, by presence or absence of lesions and first episode $v$ recurrent HSV-2 infection

\begin{tabular}{|c|c|}
\hline & $\begin{array}{l}\text { Number of days } \\
(\%)\left(n=58^{*}\right)\end{array}$ \\
\hline Oral HSV-2 shedding without lesions at any site & $25(43)$ \\
\hline $\begin{array}{l}\text { Oral HSV-2 shedding with concurrent genital } \\
\text { HSV-2 isolation } \\
\text { Oral HSV-2 shedding with oral lesions only }\end{array}$ & 32 (55) \\
\hline First episode infection & 0 \\
\hline $\begin{array}{l}\text { Recurrent infection } \\
\text { Oral HSV-2 shedding with oral and genital } \\
\text { lesions }\end{array}$ & $3(5)$ \\
\hline First episode infection & 11 (19) \\
\hline Recurrent infection & $3(5)$ \\
\hline Oral HSV-2 shedding with genital lesions only & \\
\hline First episode infection & $4(7)$ \\
\hline Recurrent infection & $12(21)$ \\
\hline
\end{tabular}

$\mathrm{OR}=2.2(95 \% \mathrm{CI} 1.1$ to $4.2 ; \mathrm{p}=0.01)$. Age, race, lifetime number of sexual partners, age at sexual debut, and HSV serology (HSV-2 $v$ HSV-1 HSV-2) did not differ between those who did $v$ did not shed HSV-2 from the mouth. As expected, frequency of sampling influenced the frequency of HSV-2 detection. The number of days of viral samples was significantly higher among people who shed HSV-2 from the mouth $v$ those who did not $(32 v 4 ; \mathrm{p}<0.001)$.

In multivariate analyses designed to clarify the relation between sexual orientation, HIV infection, and oral HSV-2 shedding, the OR for oral HSV-2 shedding was higher for HIV seropositive $v$ seronegative people, OR $=2.04$ (95\% CI 0.83 to 5.03) than for homosexual vs. heterosexual orientation, $\mathrm{OR}=1.48$ (95\% CI 0.65 to 3.35 ), suggesting that immunosuppression due to HIV-1 may be a greater determinant of HSV-2 isolation from the mouth than sexual behaviour.

HSV-2 was isolated from the mouth of 44 people on 58 days (table 2). On 25 (43\%) days, HSV-2 isolation was in absence of oral or genital lesions. At 14 days (24\%) both oral and genital lesions were observed during oral HSV-2 isolation: 11 of these days represented first episode symptomatic HSV-2 infections. However, recurrent infections were seen on $3(5 \%)$ days. On another 3 days an oral recurrent lesion was noted when HSV-2 was isolated. Oral HSV-2 shedding concurrent with genital lesions and no oral lesions was observed on 4 (7\%) days during first episode HSV-2 infection and on $12(21 \%)$ days in a recurrent infection. Overall, HSV-2 was isolated from the genital area on 32 (55\%) days of oral HSV-2 isolation. Illustrative patterns of HSV shedding from the oral and genital area of five participants are shown in figure 1.

\section{Risk of oral HSV-2 $v$ genital HSV-2 shedding}

Next, we examined the frequency of HSV-2 isolation from the mouth compared to the genital area (table 3). These analyses were limited to people from whom at least 30 oral samples for viral culture were obtained outside of the first episode episode. Of 307 people who met these criteria, 22 (7.2\%) shed HSV-2 from the mouth and $233(76 \%)$ shed HSV-2 from the genital area $(\mathrm{p}<0.001)$ (table 3$)$. Eighteen of the 233 people who shed HSV-2 from the genital area also shed HSV-2 from 
Subject 1; HSV-2 seropositive HIV seropositive man

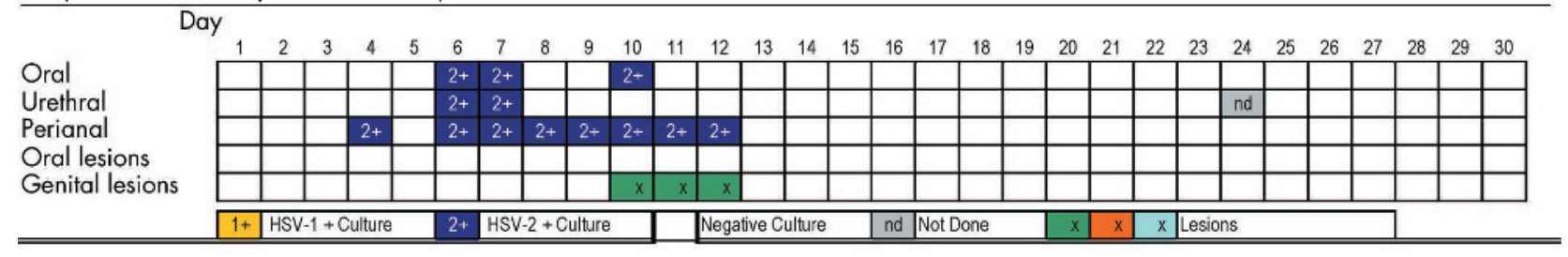

Subject 2: HSV-2 seropositive HIV seronegative man

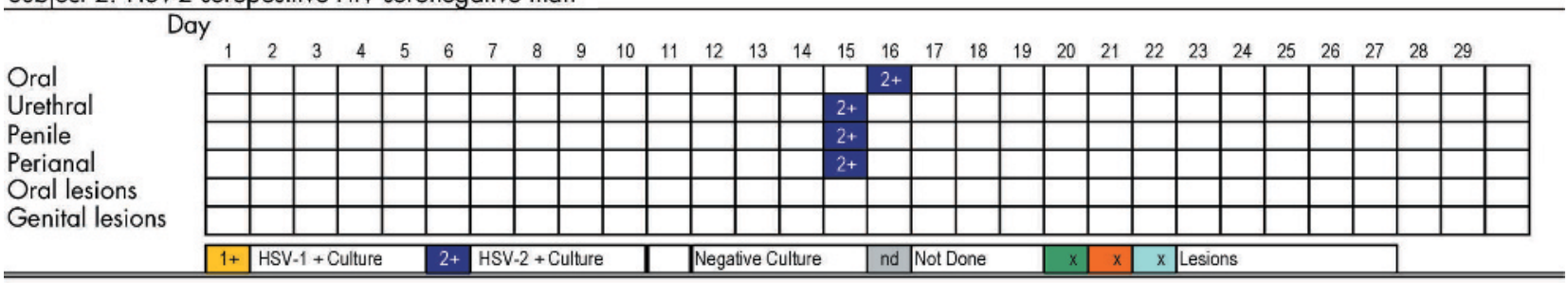

Subject 3: HSV - 1 and 2 seropositive HIV seropositive woman

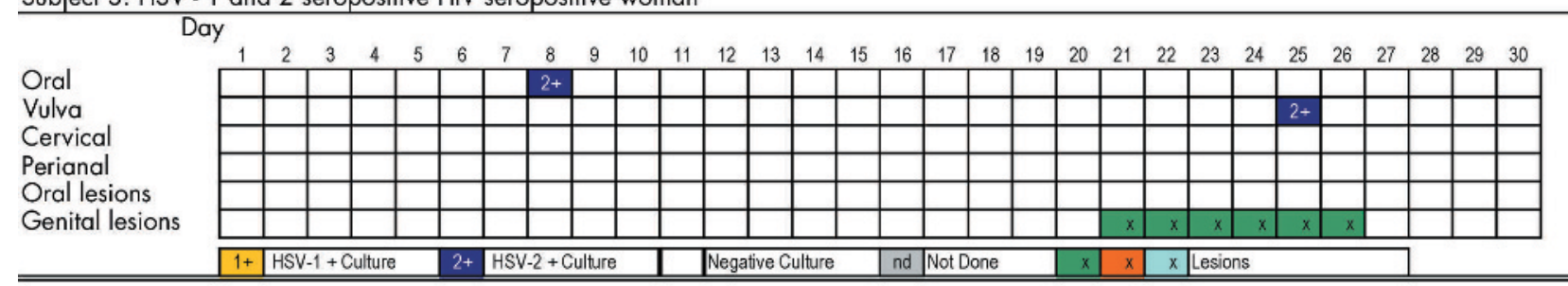

Subject 4: HSV - 1 and 2 seropositive HIV seronegative woman

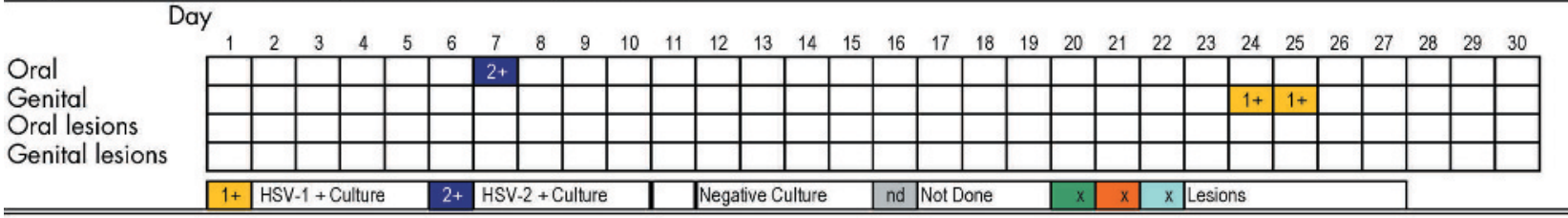

Subject 5: HSV - 1 and 2 seropositive HIV seronegative woman

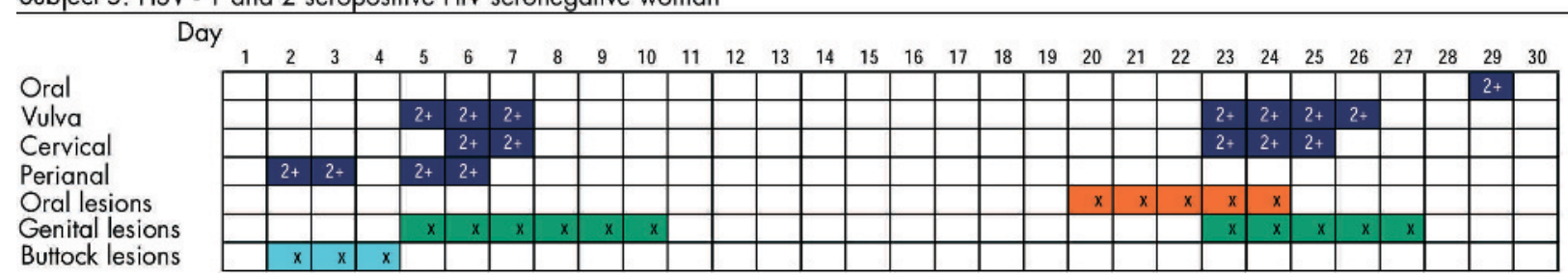

Figure 1 Illustrative patterns of viral shedding of HSV-2 in the mouth in five people participating in daily home cultures.

the mouth. The rates of shedding for HSV-2 were $0.09 \%$ of days from the mouth compared with $7 \%$ from the genital area $(\mathrm{p}<0.001)$ (table 4). HSV-2 was isolated from the mouth on 17 of $16903(0.1 \%)$ days of samples in HIV seropositive participants compared with 13 of $16733(0.08 \%)$ samples in HIV seronegative participants. Among HIV seronegative people only, the rate of oral HSV-2 shedding was four of $5599(0.07 \%)$ days in homosexual men and women compared with nine of $11134(0.08 \%)$ days among the other participants.

\section{Risk of oral HSV-2 shedding $\boldsymbol{v}$ oral HSV-1 shedding}

These analyses were restricted to people who collected more than 30 days of samples and were seropositive for both HSV1 and HSV-2. Of the 169 such people, 11 (6.5\%) had HSV-2 isolated from the mouth and 63 (37\%) had HSV-1 isolated

Table 3 Frequency of oral and genital shedding of HSV-1 and HSV-2 in people with $>30$ days of oral cultures, outside of first episode infection

\begin{tabular}{|c|c|c|c|}
\hline & $\begin{array}{l}\text { HSV-2 seropositive } \\
\text { only }(n=138)\end{array}$ & $\begin{array}{l}\text { HSV-1 and HSV-2 } \\
\text { seropositive }(n=169)\end{array}$ & $\begin{array}{l}\text { Total } \\
(n=307)\end{array}$ \\
\hline $\begin{array}{l}\text { No of people shedding HSV-2 orally } \\
\text { No of people shedding HSV-1 orally } \\
\text { No of people shedding HSV-2 genitally } \\
\text { No of people shedding HSV-1 genitally }\end{array}$ & $\begin{array}{l}11(8 \%) \\
- \\
101(73 \%) \\
-\end{array}$ & $\begin{array}{l}11(6.5 \%) \\
63(37 \%) \\
132(78 \%) \\
18(11 \%)\end{array}$ & $\begin{array}{l}22(7.2 \%) \\
- \\
233(76 \%) \\
-\end{array}$ \\
\hline
\end{tabular}


Table 4 Rates of oral and genital shedding of HSV-1 and HSV-2 in people with $>30$ days of oral cultures, outside of first episode infection

\begin{tabular}{|c|c|c|c|}
\hline & $\begin{array}{l}\text { HSV-2 only } \\
\text { ( } \mathrm{n}=138)\end{array}$ & $\begin{array}{l}\text { HSV-1 and HSV-2 } \\
(n=169)\end{array}$ & $\begin{array}{l}\text { Total } \\
(n=307)\end{array}$ \\
\hline Oral HSV-2 shedding rate & $17 / 13006(0.1 \%)$ & $13 / 20630(0.06 \%)$ & $30 / 33636(0.09 \%)$ \\
\hline Genital HSV-1 shedding rate & - & $270 / 20630(1 \%)$ & - \\
\hline Genital HSV-2 shedding rate & $925 / 15099$ (6\%) & $1675 / 21818(8 \%)$ & $2600 / 36917$ (7\%) \\
\hline Oral HSV-1 shedding rate & - & $78 / 21818(0.4 \%)$ & - \\
\hline
\end{tabular}

from the mouth $(\mathrm{p}<0.001)$. The rate of HSV -2 shedding from the mouth was $0.06 \%$ compared with $1 \%$ for HSV-1 shedding from the mouth $(\mathrm{p}<0.001)$ (table 4$)$.

\section{DISCUSSION}

Studies show that HSV-2 is infrequently isolated from orallabial lesions, suggesting that HSV-2 reactivation in the mouth is uncommon. However, in a large cohort of people with HSV-2 infection, especially those that have frequent samples over time, oral HSV-2 shedding does occur, albeit infrequently. As a manifestation of clinically symptomatic genital herpes, oral HSV-2 is usually noted in the context of first episode genital herpes. Findings suggest that HSV-2 reactivation is more frequent among HIV seropositive participants and among the men who have sex with men.

The observation that oral HSV-2 isolation is rare has been noted in other studies that have examined virus from oral herpetic ulcers or from asymptomatic people. ${ }^{3}{ }^{12}$ For example, in a sexually active college population, oral lesions cultured from 43 students yielded only HSV-1. ${ }^{13}$ However, HSV-2 has been isolated in primary infection from the mouth, especially in people who complain of a sore throat. ${ }^{14}$ Lafferty et al followed 39 adults, 27 with HSV-1 and 12 with HSV-2, with primary oral and genital HSV infections. ${ }^{3}$ In this group, the rate of recurrences caused by HSV-2 in the genital area was higher than the oral-labial recurrences because of HSV-l, 0.33 per month for genital HSV-2 compared with 0.117 per month for oral HSV-l infections. These rates of recurrences were lowest for oral-labial infections caused by HSV-2, with a rate of 0.001 per month. In vitro data suggest that HSV-2 can infect oral epithelial cells as well as HSV-1. ${ }^{15}$ Given the frequency of oral-genital contact, and the frequency of genital HSV-2 isolation, ${ }^{16-18}$ lack of oral HSV-2 isolation is surprising.

Evidence implicates both the type of (HSV-1 $v$ HSV-2) virus and the immune control at the anatomical site (oral $v$ genital) in the control of HSV reactivation. Substitution of the HSV-1 latency associated transcript for native HSV-2 sequences in animal models causes HSV-2 to reactivate from the trigeminal ganglia with the frequency typical of HSV-l. ${ }^{19}$ Immunosuppression appears to be a risk factor for oral HSV-2 reactivation, possibly for viral shedding, as suggested in our study, and for clinically evident disease, as documented in case reports of severe and atypical oral HSV-2 infection in the presence of advanced HIV infection. ${ }^{20}$ These observations support the role of the immune system in

\section{Key messages}

- Oral shedding of HSV-2 is infrequent and usually occurs without oral lesions

- Oral HSV-2 shedding can occur during new genital HSV-2 infection or during recurrent genital HSV-2 preventing reactivation of HSV-2 in the mouth in healthy hosts, but it is not clear why the immune system would be more effective at the level of the trigeminal ganglia for HSV2, and sacral ganglia for HSV-1. Most likely, an interaction between the viral genes and site specific cellular milieu is responsible for rare reactivation of HSV-2 from latency in trigeminal ganglia.

Several limitations to these data should be noted. Some people included in the analyses may have HSV-2 infection only in the genital area; as such, these people are not at risk for HSV-2 shedding from the mouth. This would underestimate the shedding rate for oral HSV-2 reported here. Mislabelling of samples as oral when they were collected from the genital area may have also occurred, but the frequency of this is unknown. Such misclassification would attenuate any relations found between oral HSV-2 shedding and predictors. Finally, people who agree to participate in daily home cultures may differ from people who decline to participate in such labour intensive studies. However, whether participation in these studies is related to the frequency of oral HSV-2 reactivation appears unlikely.

People with documented HSV-2 in the mouth may be concerned about the potential for HSV-2 transmission during intimate but not sexual contact, such as sharing utensils, as HSV-1 is well documented to spread by close but non-sexual contact. ${ }^{1}$ Given the infrequent shedding of HSV-2 from the mouth, the risk of HSV-2 transmission from such contact appears remote and patients can be reassured that they are very unlikely to transmit in non-intimate settings.

\section{ACKNOWLEDGEMENTS}

NIH grant AI-3073. The authors thank Dr Woody Spruance for suggesting these questions, and for helpful comments on the manuscript.

\section{CONTRIBUTORS}

AW, study design, data analysis, manuscript editing; ME, data extraction and review, literature review, drafting of the manuscript; EK, data analysis, manuscript editing; SS, data management and analysis; LC, study design, manuscript editing.

\section{Authors' affiliations}

A Wald, L Corey, Departments of Medicine, University of Washington, Seattle, WA, USA

A Wald, Departments of Epidemiology, University of Washington, Seattle, WA, USA

A Wald, E Krantz, S Selke, L Corey, Departments of Laboratory Medicine, University of Washington, Seattle, WA, USA

M Ericsson, Odontologiska Institutionen, Karolinska Institutet, Hudding, Sweden

L Corey, Program in Infectious Diseases, Fred Hutchinson Cancer Research Center, Seattle, WA

\section{REFERENCES}

1 Whitley R. Herpes simplex virus. In: Fields B, Knipe D, Howley P, Chanock R, Melnick J, Monath T, et al, eds. Fields' virology. 3rd ed. Philadelphia: Lippincott-Raven, 1996. 
2 Mertz G. Genital herpes simplex virus infections. Med Clin North Am 1990;74:1433-54.

3 Lafferty WE, Coombs RW, Benedetti J, et al. Recurrences after oral and genita herpes simplex virus infection: influence of anatomic site and viral type. N Engl J Med 1987:316:1444-9.

4 Brock BV, Selke S, Benedetti J, et al. Frequency of asymptomatic shedding of herpes simplex virus in women with genital herpes. JAMA 1990;263:418-420.

5 Wald A, Zeh J, Selke S, et al. Virologic characteristics of subclinical and symptomatic genital herpes infections. N Engl J Med 1995;333:770-5.

6 Wald A, Corey L. Acyclovir suppresses subclinical shedding of herpes simplex virus (letter). Ann Intern Med 1996;125:776-7

7 Krone MR, Tabet SR, Paradise M, et al. Herpes simplex virus shedding among human immunodeficiency virus- negative men who have sex with men: site and frequency of shedding. J Infect Dis 1998;178:978-82.

8 Krone MR, Wald A, Tabet SR, et al. Herpes simplex virus type 2 shedding in human immunodeficiency virus-negative men who have sex with men: frequency, patterns, and risk factors. Clin Infect Dis 2000;30:261-7.

9 Wald A, Zeh J, Selke S, et al. Reactivation of genital herpes simplex virus type 2 infection in asymptomatic HSV-2 seropositive persons. N Engl J Med 2000;342:844-50.

10 Langenberg A, Zbanyszek R, Dragavon J, et al. Comparison of diploid fibroblast and rabbit kidney tissue culture and diploid and fibroblast microtiter plate system for the isolation of herpes simplex virus. J Clin Microbiol 1988;26:1772-4

11 Ashley RL, Militoni J, Lee F, et al. Comparison of western blot (Immunoblot) and glycoprotein G-specific immunodot enzyme assay for detecting antibodies to herpes simplex virus types 1 and 2 in human sera. J Clin Microbiol 1988;26:662-7.
12 Wolff $M H$, Schmitt J, Rahaus $M$, et al. Clinical and subclinical reactivation of genital herpes virus. Intervirology 2002;45:20-3.

13 Docherty JJ, Trimble JJ, Roman SR, et al. Lack of oral HSV-2 in a college student population. J Med Virol 1985; 16:283-7.

14 Corey L, Adams HG, Brown ZA, et al. Clinical course of genital herpes simplex virus infections in men and women. Ann Intern Med 1983;48:973.

15 Yura $\mathrm{Y}$, lga $\mathrm{H}$, Kondo $\mathrm{Y}$, et al. Herpes simplex virus type 1 and type 2 infection in human oral mucosa in culture. J Oral Pathol Med 1991;20:68-73.

16 Lowhagen GB, Tunback P, Andersson K, et al. First episodes of genital herpes in a Swedish STD population: a study of epidemiology and transmission by the use of herpes simplex virus (HSV) typing and specific serology. Sex Transm Infect 2000;76:179-82.

17 Vyse AJ, Gay NJ, Slomka MJ, et al. The burden of infection with HSV-1 and HSV-2 in England and Wales: implications for the changing epidemiology of genital herpes. Sex Transm Infect 2000;76:183-7.

18 Lafferty WE, Downey L, Celum C, et al. Herpes simplex virus type 1 as a cause of genital herpes: impact on surveillance and prevention. $J$ Infect Dis 2000;181:1454-7.

19 Yoshikawa T, Hill J, Stanberry L, et al. The characteristic site-specific reactivation phenotypes of HSV-1 and HSV-2 depend upon the latencyassociated transcript region. J Exp Med 1996;184:659-64.

20 Husak R, Tebbe B, Goerdt S, et al. Pseudotumour of the tongue caused by herpes simplex virus type 2 in an HIV-1 infected immunosuppressed patient. $\mathrm{Br} J$ Dermatol 1998;139:118-21.

21 MacPhail LA, Greenspan D, Schiodt M, et al. Acyclovir-resistant, foscarnetsensitive oral herpes simplex type 2 lesion in a patient with AIDS. Oral Surg Oral Med Oral Pathol 1989:67:427-32.

\section{CHESTER CHRONICLES}

\section{Paddy}

was well satisfied! Hours of laptopping, configuring, enhancing, deleting, and modifying had now produced a very comprehensive HIV PowerPoint presentation. There were pie charts, histograms, busy tables, references, $\mathrm{p}$ values of perfection, and more mutations than a Van Helsing movie. All I needed now was a gentle introduction-a "hook" as they call it. Something to grab the audience's attention while they munched away at the crisp-free (too noisy!) lunch packs at the BASHH GSK symposium in beautiful Bath. A recent expedition to the local Welsh mountains provided some stunning backdrops and suddenly there was the slide. It both alarmed and startled me. It was me and the dog halfway up a Welsh scree slope. At first glance I couldn't tell us apart. It had started to happen. I was beginning to look like my dog! I had heard of this sort of thing before, but never seen the proof. Not only was the hair identical, but we both bore the same bemused and bewildered expression. Shocked though I was, I realised that I had at least found my hook. This slide would be a source of comfort for all those other animal owners who thought that they were the only ones undergoing this phenomenon.

The day came, up I stood, and away I went. When the dog and I appeared in the Welsh mountain the munching stopped. The slide had struck home and I now had their undivided attention and was able to lay on the heavy stuff. My co-presenters Martin and Anna also did brilliantly, and at the end of the session there was a good feeling.

Over the next two days at the conference, several people collared me in various locations, indicating they had a question they needed answering about my talk. Now, mutations, genotyping, phenotyping, and virtual editions of the same leave me wanting to lie down in a darkened room. However, time and time again, my fears proved unfounded, as the most technically demanding question every time was, "what's the dog's name?" "He's called Paddy." Paddy was a big hit.

Now, I was once accused of being a triumph of style over substance by a mischievous colleague. However, I regard that as a compliment. Oscar Wilde said-there's only one thing worse than being talked about, and that is not being talked about. Being remembered is critically important for a

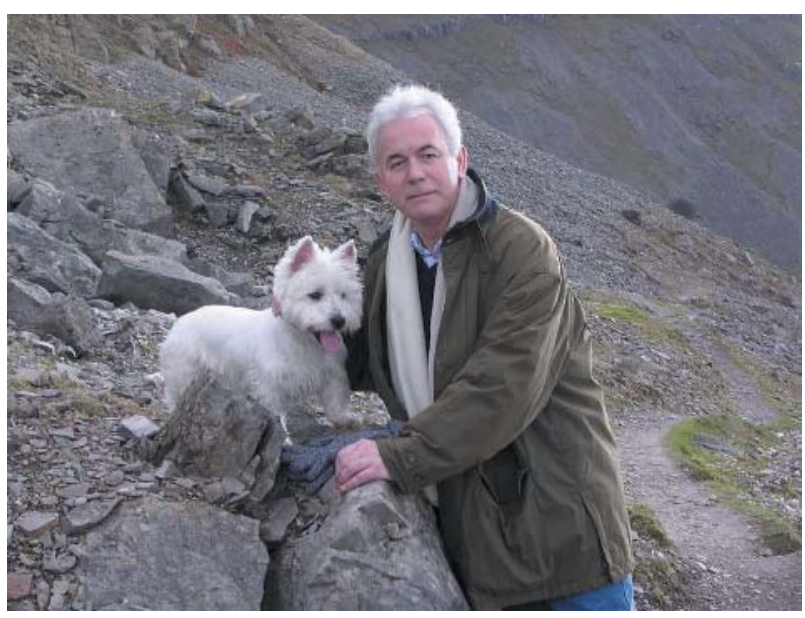

speaker. It's even better if you are remembered in a positive, amusing, and interesting manner. People rarely get or want technical data from a talk. They want a flavour, intrigue, and your personal slant, rather than bald facts which can be far more readily assimilated in printed form. So what-if I am lumbered with the label of "the guy who looked like his dog." At the end of our session in the hall there was an air of contentment. The early finish was the final icing and I felt we had gone some way towards George Bernard Shaw's epitome of good speaking- "I have never yet heard a talk that could not have been louder, shorter, or funnier."

Later that day, I was again pleased to overhear two delegates discussing "Dr O'Mahony's talk" and saying how they absolutely must get him for their upcoming autumn conference. I proudly said I would be delighted to travel to their neck of the woods and do my thing, only to embarrassingly discover that it was Paddy the dog that they had in mind.

C O'Mahony

Countess of Chester Hospital NHS Trust, Chester CH2 IUL, UK colm.omahony@coch.nhs.uk doi: $10.1136 /$ sti.2004.011874 


\section{PostScript}

\section{LETTER}

\section{Penile injection of foreign bodies in eight Thai patients}

In the past, the presence of a large sexual organ was regarded as a symbol of strong body composition, especially with regard to sexuality. Foreign body injection into the penis for the purpose of augmenting the penile contour used to be culturally popular in some primitive communities although this practice became less fashionable after the early 1900s. The practice has continued in some parts of the world as evidenced by reports from some Asian and eastern Europe countries. ${ }^{1-3}$

Here, I present a summary of the clinical history of eight Thai patients who presented to the physician with injected foreign bodies in their penis (table 1). The age range was 24-52 years (mean 36.3 years). The main presenting compliant of the patients was penis pain $(75 \%)$ : no late complications were detected. In previous reports, the patients usually presented with late complications such as penile ulceration and successful treatment was difficult to achieve. ${ }^{1-3}$ Most of performed self injection $(87.5 \%)$ and the average period of injection was 1.8 years. All patients underwent penile injection on the advice of friends, usually for the purpose of increasing their sexual attraction to potential partners. Unlike previous reports, ${ }^{1-3}$ the common injectable agents were Vaseline and olive oil. The probable explanation is that both Vaseline and olive oil are more available than silicone or paraffin in Thailand. The self injection of a foreign body may predispose the patient to subsequent infection. All patients were advised to undergo surgical removal of the residual foreign material and surrounding granulomatous tissue reaction. None of the cases reported sharing a needle with a friend during the injection process and the seven patients who agreed to undergo surgery were HIV seronegative on preoperative screening for HIV antibodies.

V Wiwanitkit

Department of Laboratory Medicine, Faculty of Medicine, Chulalongkorn University, Bangkok, Thailand 10330; wviroj@pioneer.netserv.chula.ac.th doi: $10.1136 /$ sti.2004.011064

Accepted for publication 8 April 2004

\section{References}

1 Lee T, Choi HR, Lee YT, et al. Paraffinoma of the penis. Yonsei Med J 1994;35:344-8.

2 Gfesser M, Worret WI. Paraffinoma of the penis. Hautarzt 1996:47:705-7.

3 Lighterman L. Silicone granuloma of the penis. Case reports. Plast Reconstr Surg 1976;57:517-9.

\section{CORRECTION}

doi: 10.1136/sti.2003.007823corrl

In the August issue of the journal there was a mistake in the paper by A Wald et al (Oral shedding of herpese simplex virus type 2 . Sex Transm Infect 2004;80:272-6). In table four the first column, second line currently states "genital HSV-1 shedding rates", however, it should read "oral hsv-l shedding rates" and on the fourth line "oral HSV-1 shedding rate" should read as "genital HSV-1 shedding rate.

Table 1 Characteristics of the eight Thai men who underwent penile injections

\begin{tabular}{|c|c|c|c|c|c|c|c|c|}
\hline \multirow[b]{2}{*}{ No } & \multirow[b]{2}{*}{ Age (years) } & \multirow[b]{2}{*}{ Chief complaints } & \multicolumn{4}{|l|}{ History } & \multirow[b]{2}{*}{ Final treatment } & \multirow[b]{2}{*}{$\begin{array}{l}\text { Anti-HIV } \\
\text { serology }\end{array}$} \\
\hline & & & Type & Who inject? & Reason & $\begin{array}{l}\text { Period } \\
\text { (month) }\end{array}$ & & \\
\hline 1 & 31 & Penis pain & $\begin{array}{l}\text { Vaseline, } \\
\text { paraffin }\end{array}$ & Patient & Sexual purpose & 12 & Surgical removal & Negative \\
\hline 2 & 25 & Penis pain & Olive oil & Patient & Sexual purpose & 36 & Surgical removal & Negative \\
\hline 3 & 24 & Penis pain & Olive oil & Patient & Sexual purpose & 48 & Surgical removal & Negative \\
\hline 4 & 46 & Penis pain & Olive oil & Patient & Sexual purpose & 36 & Surgical removal & Negative \\
\hline 5 & 24 & Penis pain & Vaseline & Patient & Sexual purpose & 2 & Surgical removal & Negative \\
\hline 6 & 52 & Fear for penis cancer & Vaseline & Patient & Sexual purpose & 12 & Surgical removal & Negative \\
\hline $7^{*}$ & 52 & Penis pain & Vaseline & Patient's friend & Sexual purpose & 6 & Surgical removal & Negative \\
\hline 8 & 36 & Penis pain & Olive oil & Patient & Health belieft & 24 & Lost to follow up & Unknown \\
\hline
\end{tabular}

*This patient had previously injected foreign material into his penis which had been removed surgically 10 years previously. †Belief that a large penis brings good health. 